\title{
A Harmonized Probabilistic Seismic Hazard Assessment for Northern China-Pakistan Economic Corridor
}

\author{
Changlong Li \\ Institute of Geophysics, China Earthquake Administration, Beijing 100081, China.

\section{中巴经济走廊北部协调的概率地震危险性分析 李昌珑 \\ 中国地震局地球物理研究所, 北京 100081}

\begin{abstract}
The China-Pakistan Economic Corridor (CPEC) has many strong earthquakes and tectonic activities. In recent years, different probability seismic hazard assessment (PSHA) projects has been done around the area. This paper made a harmonized PSHA for this area. This paper concluded that in the most areas of northern CPEC, the Peak Ground Acceleration (PGA) with $10 \%$ probability of exceedance in 50 years is around $0.2 \mathrm{~g} \sim 0.3 \mathrm{~g}$, and northern Pakistan has the highest seismic hazard along the northern CPEC.
\end{abstract}

Keywords: China-Pakistan Economic Corridor; Seismic hazard; Model harmonization; Peak Ground Acceleration

\section{摘要 \\ 中巴经济走廊强震频发, 构造活动强烈。近 年来, 已有多家机构在周边地区开展了概率 地震危险性分析工作。本文对该地区的地震 危险性结果进行了协调和统一。本文的结论 有, 在中巴经济走廊北部大部, 50 年超越概 率 $10 \%$ 的峰值加速度值在 $0.2 \mathrm{~g}^{2} 0.3 \mathrm{~g}$ 之间, 巴基斯坦北部的地震危险性最高。}

关键词: 中巴经济走廊; 地震危险性; 模型 协调; 峰值加速度

\section{Introduction}

Strong earthquake ground motion can cause destruction of the buildings, and lead to earthquake disasters. It is of great help to prevent earthquake disasters by providing appropriate seismic fortification parameters for structural design. Therefore, seismic hazard and risk assessment has important practical and social value.

Different institutions have made Probabilistic Seismic Hazard Assessment (PSHA) works in different areas. Therefore, along those area borders, there may be several PSHA results because different institutions may use different PSHA methods and build different hazard models. If we want to get a harmonized PSHA result for the whole area, we should do seismic hazard model harmonization at the borders. This is what we managed to do in this paper.

We took the northern part of the China-Pakistan Economic Corridor (CPEC) as the study area (Figure 1). The CPEC connects Xinjiang and Pakistan, and is an important economic way in the One Road One Belt Project. The northern part of CPEC is in Tienshan-Karakoram area, and is situated at the center of Eurasia Continent, where has 
many tectonic activities. Three PSHA results have been made in this area, which are PSHA for Central Asia, the Middle East and China respectively. Northern CPEC is right at the intersection of these areas, and different projects give different hazard results in the same area. Consequently, it is meaningful to make a harmonized PSHA in the area.

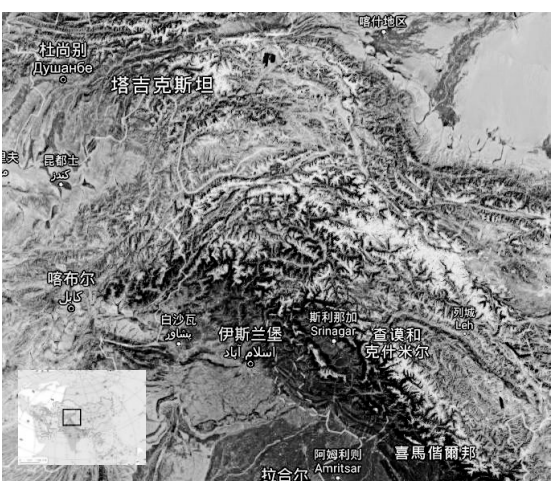

Figure 1. Study area - Northern CPEC

Bindi et al. (2012) conducted a PSHA study in Central Asia. In this study, area source model is used. The seismicity model only considers shallow earthquakes with focal depth less than $50 \mathrm{~km}$. Seismic hazard parameters use macro-seismic intensity. The study used OpenQuake to produce a intensity distribution with $10 \%$ probability of exceedance in 50 years of the Central Asia (Figure 2). The results show that the intensity of VIII in the region with the highest seismic hazard in Central Asia is less than 475 years in the vicinity of the South Tienshan area.

In 2005, Danciu et al. (2015) made PSHA for the Middle East. They weighted averaged the hazard result by area source model and fault source model, and got a hazard map of Peak Ground Acceleration (PGA) with 10\% probability of exceedance in 50 years of the area (Figure 3).

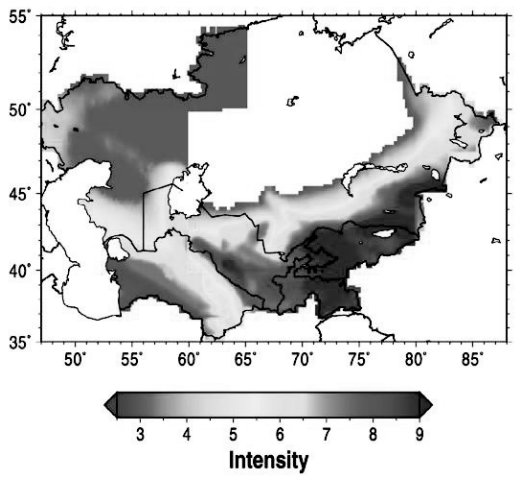

Fig. 2 Intensity map with $10 \%$ probability of exceedance in 50 years of Central Asia (Bindi et al, 2015)

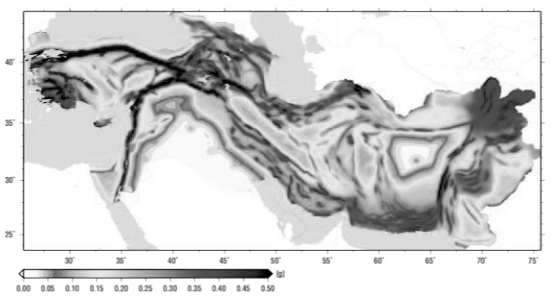

Figure 3 Seismic hazard map of PGA with 10\% probability of exceedance in 50 years of the Middle East

In 2016, the fifth version of Seismic Hazard Map of China (Figure 4, GB 18306-2015.) was published. This map shows seismic hazard with $10 \%$ probability of exceedance in 50 years of China. And there have also been other researches on seismic hazard of China (Yan et al., 2013).

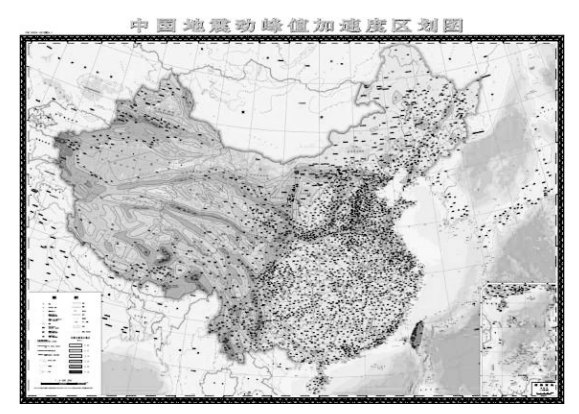

Figure 4. The fifth version of Seismic Hazard Map of China (GB 18306-2015) 
Thanks to the cooperation between ETH Zurich, Global Earthquake Model (GEM) Foundation and Institute of Geophysics, China Earthquake Administration (CEA), we were able to work together and engaged in producting a harmonized seismic hazard map in Northern CPEC. The work will be introduced below.

\section{Seismic Hazard Model Harmonization for Northern CPEC}

Seismogenic source model

\section{Central Asia}

Seismogenic source model in Central Asia is built by the project of Earthquake Model of Central Asia (EMCA, Bindi et al. 2012), as shown in Figure 5. Central Asia is separated into ten seismic belts (in thick red lines) and 131 seismogenic sources (in thin red lines) in total.

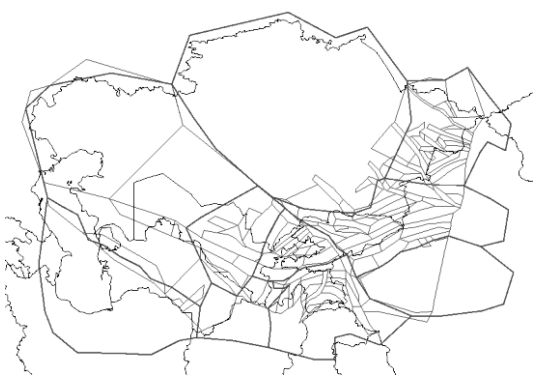

Figure 5. Seismogenic sources of EMCA (Bindi et al. 2012)

\section{The Middle East}

Seismogenic source model in the Middle East is built by the project of Earthquake Model of the Middle East (EMME, Danciu et al, 2015), as shown in Figure 6. The Middle East Area is separated into three tectonic types: Active Shallow Crust (ASC, in white), Stable Continental Crust (SCC, in gray) and Subduction Intraslab (SI, in brown). In the Middle East, there are 213 ASCs, eleven SCCs and six SIs in total.

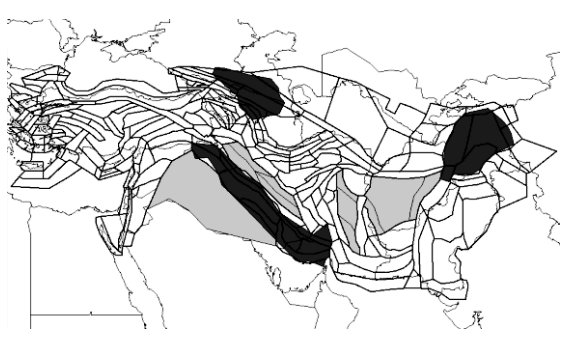

Figure 6. Seismogenic sources of EMME (Danciu et

$$
\text { al, 2015) }
$$

\section{China}

Seismogenic source model in the Middle East is built by the working group of the fifth version of Seismic Hazard Map of China (Gao et al, 2014), as shown in Figure 7 and 8. China is separated into 29 seismic belts (Figure 7) and 1643 seismogenic sources (Figure 8) in total.

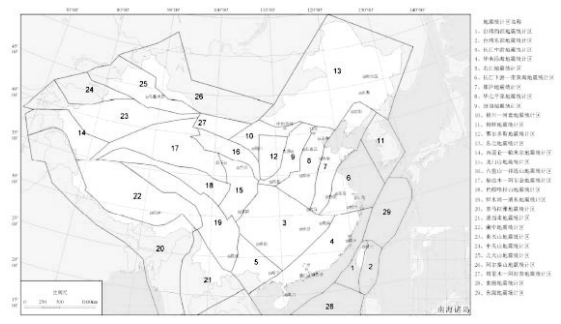

Figure 7. Seismic belts in China (Gao et al, 2014)

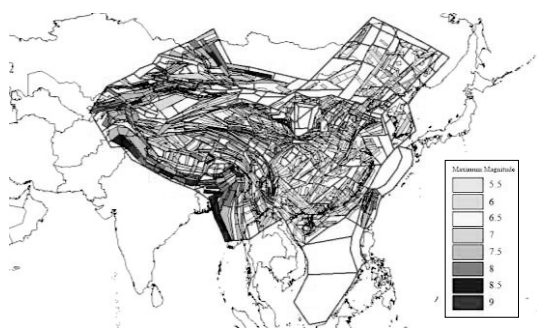

Figure 8. Seismogenic sources in China (Gao et al, 2014)

\section{Source model harmonization}

We can see sources by three institutions in Northern CPEC as shown in Figure 9. To do harmonization, we managed to delete entire pieces of overlapped sources as shown in Figure 10. Then we sew the edges and gaps, as shown in Figure 11. 


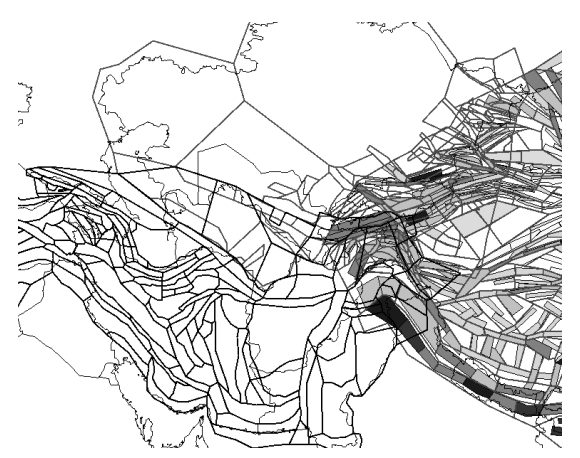

Figure 9. Sources by three institutions in Northern CPEC

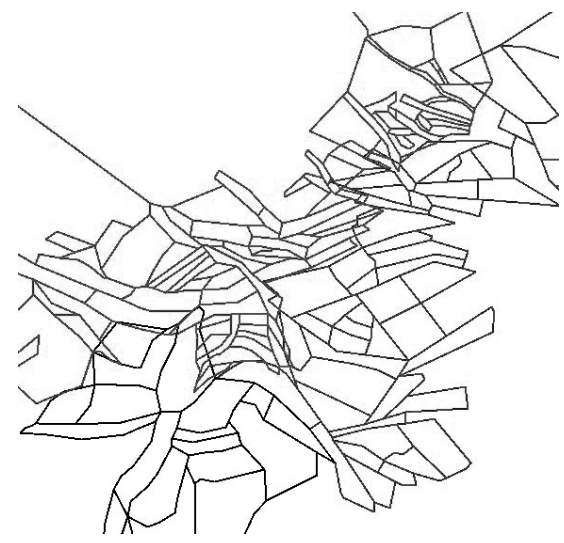

Figure 10. Sources after deleting entire pieces of overlapped ones

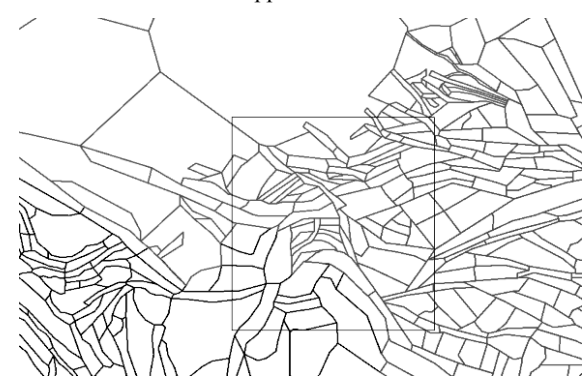

Figure 11. Sources after sewing edges

\section{Changing seismicity parameters}

For the sources whose areas are changed, their seismicity parameters should also be changed. For one source, it has a-value and b-value according to Gutenberg-Richter relationship. We suppose its original a-value is a, and a' after changing. Then a' can be calculated by

$$
a^{\prime}=\lg \left(10^{a} \cdot \frac{S^{\prime}}{S}\right)
$$

Where S and S' are source's areas before and after harmonization. Then we get a harmonized source separation of South Tienshan as shown in Figure 12.

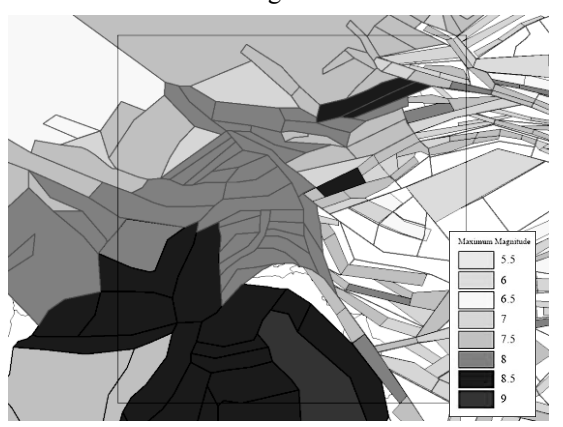

Figure 12. Harmonized source separation of Northern CPEC

\section{Choosing Ground Motion Prediction Equation (GMPE)}

The harmonized source model should use the same GMPE model. We chose Yu et al. (2013)'s GMPE which is used in Seismic hazard map of China. The equation is as follows:

$$
\lg Y=A+B M+C \lg \left(R+D e^{E M}\right)
$$

where $Y$ is ground motion parameters, $M \mathrm{i}$ s magnitude, $R$ is epicenter, $A, B, C, D$ an d $E$ are constants.

\section{Seismic hazard result}

The seismic hazard map of PGA with $10 \%$ probability of exceedance in 50 years of Northern CPEC by harmonized model is shown in Figure 13. From the hazard map, we can find western part of Northern CPEC has the highest seismic hazard. In Central Xinjiang and the center of Central Asia, seismic hazard is low. 


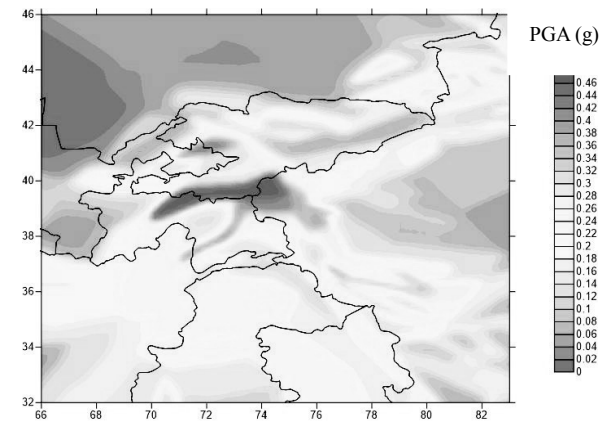

Figure 13. Seismic hazard map of PGA with $10 \%$ probability of exceedance in 50 years of Northern CPEC by harmonized model

\section{Conclusion}

From the study above, we can get several conclusions as follows:

1. Western part of Northern CPEC has the highest seismic hazard.

2. In Central Xinjiang and the center of Central Asia, seismic hazard is low.

3. In Northern Xinjiang and Northern Kazakhstan, Seismic hazard is low.

There are also some topics that need discussion:

1. When dealing with seismicity parameter harmonization, we took a simple way that change a source's parameter according to its area change with the assumption that the seismicity is the same on unit area. There is also a more precise way that using earthquake catalog to get the seismicity parameter.

2. Along borders, different models lead to different hazard result for the same place. The reason of the difference needs more study in the future.

3. We took the GMPE of Yu et al. (2013) as the harmonized GMPE. It needs to study if it is the most suitable one.

\section{Acknowledgement}

Thanks to Xinjiang Earthquake Agency who provided data of seismogenic structures in Xinjiang for this study. This study is sponsored by National Key R\&D Program of China (2017YFC1500405), Earthquake Emergency Junior Key Fund of CEA (CEA_EDEM 201816) and Fundamental Research Specific Fund (DQJB17T04).

\section{Reference}

[1] Bindi D, Abdrakhmatov K, Parolai S, et al. 2012. Seismic hazard assessment in Central Asia: Outcomes from a site approach. Soil Dynamics and Earthquake Engineering, 37: 84-91.

[2] Danciu L, Giardini D, Sesetyan K. 2015. Seismic Hazard Assessment in the Middle East Region. Earthquake Model of the Middle East Region Project.

[3] Gao Z W, Chen G X, Zhou B G, et al. (2014). The principles and techniques of identifying seismotectonic province in new national seismic zoning map of China - an example of East China with middle seismic activity. Technology for Earthquake Disaster Prevention (in Chinese), 9(1): 1-11.

[4] General Administration of Quality Supervision, Inspection and Quarantine of the People's Republic of China, China National Standardization Administration Committee. 2015. Seismic hazard map of China. GB 18306-2015.

[5] Yan J P, Li S S, Bai J, et al. 2013. The Spatial Symmetry Axis of Earthquake Hazard in China. Journal of Risk Analysis and Crisis Response, 3(1): 59-64.

[6] Yu Y X, Li S Y, Xiao L. 2013. Development of Ground Motion Attenuation Relations for the New Seismic Hazard Map of China. Technology for Earthquake Disaster Prevention (in Chinese), 8(1): 24-33. 